\title{
La biolixiviación como pretratamiento de menas auríferas refractarias en matriz de sulfuros ${ }^{(*)}$
}

\author{
N. Iglesias ${ }^{(*)}$, F. Carranza ${ }^{(*)}$ e I. Palencia ${ }^{(*)}$
}

\begin{abstract}
Resumen En este trabajo se analiza la eficacia de la biolixiviación en el pretratamiento de un conjunto de minerales auríferos en los que la refractariedad viene provocada por la presencia de sulfuros metálicos. Se estudian tres tipos de matrices: pirita, arsenopirita y sulfuros de cobre. Se concluye que la biolixiviación es un pretratamiento eficaz para estos tipos de menas refractarias de oro. En el caso de menas en matriz de pirita es necesario el contacto directo entre el sulfuro y los microorganismos. En el caso de menas en matriz de sulfuros de cobre y/o de sulfuros de arsénico, la biolixiviación puede realizarse por un mecanismo de contacto indirecto con separación de efectos, lo que permite alcanzar una cinética mucho más rápida que la de los procesos convencionales de biolixiviación. Esta mejora cinética reduce los tiempos de operación con el consecuente abaratamiento de instalaciones y coste de operación. Este hecho, en un futuro, puede significar la ampliación de las reservas tratables de menas de oro mediante la incorporación de minerales que actualmente no tienen la consideración de tales por no existir procesos tecnológicos con viabilidad económica para su tratamiento.
\end{abstract}

Palabras clave: Biolixiviación. Mena aurífera refractaria.

\section{Bacterial leaching as a pretreatment of refractory gold ores in sulphide matrix}

\begin{abstract}
In this paper the effectiveness of bacterial leaching as a pretreatment of gold ores bearing sulphide minerals is analysed. Three kinds of matrixes are studied: pyrite, arsenopyrite and copper sulphides. It is concluded that bacterial leaching is an effective pretreatment for these refractory gold-bearing ores. In the case of a pyrite matrix a direct contact between the mineral and the microorganisms is necessary. In the case of copper or/and arsenic sulphide matrix, bacterial leaching may be carried out by indirect contact mechanism with effects separation, thus allowing faster kinetics than conventional bioleaching processes. This kinetic improvement reduces operation times and so the capital and operating costs. In a future, this fact may result in the enlargement of the profitable gold ore reserves, incorporating minerals that, at present, are not considered gold ores since there is not a technology, feasible from an economic point of view, for their treatment.
\end{abstract}

Keywords: Bacterial leaching. Refractory gold ores.

\section{INTRODUCCIÓN Y ANTECEDENTES BIBLIOGRÁFICOS}

Desde finales del siglo XIX, la extracción de metales preciosos se realiza, normalmente, por el

$(\bullet)$ Trabajo recibido el día 30 de junio de 1997.

(*) Dpto. de Ingeniería Química. Facultad de Química. Universidad de Sevilla. P. García González, s/n (Edif. de Química). 41012-Sevilla (España). método de cianuración. Desde entonces, este proceso ha conocido continuas mejoras y, en la actualidad, se sigue usando dada su simplicidad y capacidad para tratar los minerales más diversos.

Las reacciones que tienen lugar durante la disolución de oro en medio cianuro se han estudiado con profundidad. La mayoría de los autores coinciden en que la reacción global que se da es:

$2 \mathrm{Au}+4 \mathrm{NaCN}+1 / 2 \mathrm{O}_{2}+\mathrm{H}_{2} \mathrm{O} \rightarrow 2 \mathrm{NaAu}(\mathrm{CN})_{2}+2 \mathrm{NaOH}$ 
En un sistema de este tipo, el oro se disuelve con gran efectividad. Los únicos requerimientos son que el oro esté libre y limpio, que la solución no contenga impurezas que puedan inhibir la reacción, y que haya un adecuado suministro de oxígeno en la solución durante todo el período que dure la reacción.

La cianuración puede llevarse a cabo en un proceso estático (en pilas percoladas o inundadas) o a través de un proceso dinámico (en tanques agitados).

El oro, disuelto como complejo cianurado, se recupera normalmente mediante el proceso "MerrilCrowe", que consiste, básicamente, en la precipitación del oro con polvo de zinc, según:

$$
2 \mathrm{NaAu}(\mathrm{CN})_{2}+\mathrm{Zn} \rightarrow \mathrm{Na}_{2} \mathrm{Zn}(\mathrm{CN})_{4}+2 \mathrm{Au}
$$

Este proceso requiere una posterior purificación y fusión del precipitado de oro para obtener el bullón, que es como se denomina a la barra de oro producida.

Otra manera de recuperar el oro disuelto es mediante la adsorción con carbón activado. Este es el método que siguen los procesos "carbón en pulpa" (C.I.P.), "carbón en lixiviación" (C.I.L.) y "carbón en lixiviación con oxígeno" (C.I.L.O.). En los dos últimos, la lixiviación y la adsorción se realizan simultáneamente.

Posteriormente, se realiza la desorción del carbón y se recupera el oro por electrólisis.

Después del proceso de cianuración, las extracciones de oro y plata deben estar entre el 90-96\%. Sin embargo, existen algunos materiales de los cuales se extrae solamente entre el 5-60\% de su contenido en oro. Se trata de menas refractarias al proceso de cianuración estándar.

En general, se considera que una mena de oro es refractaria si el nivel de extracción mediante un proceso de cianuración convencional dinámica no supera el $80 \%$, incluso después de una fina molienda (1), y no permite una recuperación económica de este metal (2-6).

La refractariedad puede tener su origen en fenómenos de distinta naturaleza. Puede tratarse de una refractariedad física, en la que el oro está ocluido en una matriz y el cianuro no puede acceder a él. Puede ser una refractariedad química, debida a la presencia de especies que se combinan y consumen el cianuro y el oxígeno necesarios para complejar el oro. Puede tratarse de un fenómeno electroquímico en el que el oro se pasiva y, en consecuencia, no se disuelve. Y puede deberse también a la presencia de especies carbonáceas que adsorben el complejo de oro cianurado.

En todos los casos, estos minerales deben ser tratados previamente, ya sea para liberar el metal precioso encapsulado y permitir así su contacto con el cianuro, o para destruir las especies que impiden que tenga lugar la cianuración y la existencia del complejo cianurado en disolución.

La tabla I muestra los tratamientos más empleados para diferentes tipos de minerales refractarios, así como los problemas más comunes que estos implican.

Una alternativa a estos métodos puede ser la biolixiviación, proceso biológico en el que los sulfuros son oxidados por la acción de microorganismos.

La aplicación de la biolixiviación al tratamiento de menas refractarias es un concepto relativamente nuevo en comparación con la tostación y la oxidación química, y se está estableciendo rápidamente como una alternativa viable.

A través de ensayos comparativos se ha podido demostrar que la biolixiviación iguala e, incluso, supera a estos procedimientos en términos de

TABLA I.- Tipos de minerales y tratamientos convencionales

TABLE I.-Conventional pretreatments

\begin{tabular}{|l|l|l|}
\hline \multicolumn{1}{|c|}{ Tipo de mineral } & \multicolumn{1}{|c|}{ Tratamiento } & \multicolumn{1}{c|}{ Problemas } \\
\hline (1) Oro libre & Concentración gravimétrica, cianuración & No \\
\hline (2) Oro con sulfuros & $\begin{array}{l}\text { Flotación, aireación con cal, tostación, } \\
\text { calcinación y cianuración }\end{array}$ & $\begin{array}{l}\text { Pérdidas de recuperación de oro, } \\
\text { generación de dióxido de azufre }\end{array}$ \\
\hline $\begin{array}{c}\text { (3) Oro con minerales de } \\
\text { arsénico y antimonio }\end{array}$ & Flotación, tostación, lavado y cianuración & $\begin{array}{l}\text { Pérdidas de recuperación de oro, } \\
\text { generación de dióxido de azufre, } \\
\text { generación de compuestos tóxicos } \\
\text { de arsénico y antimonio }\end{array}$ \\
\hline (4) Oro con pórfidos de cobre & Fusión para el cobre. Oro en barros anódicos & No \\
\hline $\begin{array}{c}\text { (5) Oro con minerales de } \\
\text { plomo y cinc }\end{array}$ & Tostación, lixiviación, lavado y cianuración & $\begin{array}{l}\text { Generación de dióxido de azufre, } \\
\text { generación de compuestos tóxicos }\end{array}$ \\
\hline (6) Minerales carbonáceos & Calcinación y cianuración & Pérdidas de recuperación de oro \\
\hline
\end{tabular}


recuperación de metal en cianuración y de la economía del proceso (7).

Dentro de los microorganismos empleados en biolixiviación destaca la bacteria Thiobacillus ferrooxidans que es un bacilo corto, de aproximadamente $0,5 \times 1 \mu \mathrm{m}$, de extremos redondeados, gramnegativo, mótil, flagelado y no formador de esporas. En general, esta bacteria se encuentra aislada o emparejada y rara vez forma cadenas. Se caracteriza por ser quimiolitótrofa, pues obtiene de la oxidación del ion ferroso y de formas reducidas del azufre la energía necesaria para su crecimiento y demás procesos vitales. Es una bacteria autótrofa estricta ya que utiliza el $\mathrm{CO}_{2}$ como única fuente de carbono celular. Vive en condiciones ácidas y aerobias. Presenta actividad metabólica importante entre los 20 y los $40{ }^{\circ} \mathrm{C}$ de temperatura.

La biolixiviación puede seguir dos mecanismos: el mecanismo de contacto directo, que requiere un íntimo contacto físico entre la bacteria y el mineral a lixiviar, y el de contacto indirecto en el que el sulfuro es oxidado por el ion férrico que la bacteria genera.

En el mecanismo de contacto indirecto se pueden distinguir dos fenómenos. Por una parte, el ion Fe(III) oxida al sulfuro metálico, según la ecuación química general:

$$
\mathrm{MS}+2 \mathrm{Fe}^{3+} \rightarrow \mathrm{M}^{2+}+2 \mathrm{Fe}^{2+}+\mathrm{S}^{0}
$$

donde $\mathrm{M}$ es un metal. El Fe(II) y el azufre elemental producido en la reacción 3 son oxidados por las bacterias a $\mathrm{Fe}(\mathrm{III})$ y ácido sulfúrico respectivamente, según:

$$
\begin{array}{rr}
4 \mathrm{FeSO}_{4}+\mathrm{O}_{2}+2 \mathrm{H}_{2} \mathrm{SO}_{4} \stackrel{\text { bacteria }}{\rightarrow} 2 \mathrm{Fe}_{2}\left(\mathrm{SO}_{4}\right)_{3}+\underset{[\mathrm{r} 4]}{2 \mathrm{H}_{2} \mathrm{O}} \\
2 \mathrm{~S}+2 \mathrm{H}_{2} \mathrm{O}+3 \mathrm{O} \stackrel{\text { bacteria }}{\rightarrow} 2 \mathrm{H}_{2} \mathrm{SO}_{4}
\end{array}
$$

En el caso de la pirita, el ataque se da, casi exclusivamente, a través de un mecanismo de contacto directo, según la reacción:

$$
4 \mathrm{FeS}_{2}+15 \mathrm{O}_{2}+2 \mathrm{H}_{2} \mathrm{O} \stackrel{\text { bacteria }}{\rightarrow} 2 \mathrm{Fe}_{2}\left(\mathrm{SO}_{4}\right)_{3}+2 \mathrm{H}_{2} \mathrm{SO}_{4}
$$

En la tabla II se presentan los resultados de las experiencias de biolixiviación de menas refractarias de oro realizadas en los últimos años en laboratorio (8-12). En todos los casos, el contacto entre la mena, el medio de cultivo y los microorganismos se ha llevado a cabo de forma simultánea. El microorganismo más empleado, con mucha diferencia, es la bacteria Thiobacillus ferrooxidans, siendo muy limitado el número de trabajos realizados con termófilos. En general, el uso de termófilos no está justificado ni desde el punto de vista energético ni

\begin{tabular}{|c|c|c|c|c|c|c|c|c|}
\hline \multirow[b]{2}{*}{ Matriz } & \multirow[b]{2}{*}{ Bacteria } & \multirow[b]{2}{*}{$\begin{array}{c}\text { Temp., } \\
{ }^{\circ} \mathrm{C}\end{array}$} & \multirow[b]{2}{*}{$\begin{array}{c}\text { Modo } \\
\text { operación }\end{array}$} & \multirow[b]{2}{*}{$\begin{array}{c}\mathrm{Dp} \\
\mathrm{p} / \mathrm{p} \%\end{array}$} & \multirow[b]{2}{*}{$\begin{array}{c}\text { Tiempo, } \\
\text { días }\end{array}$} & \multirow[b]{2}{*}{$\begin{array}{c}\text { Óxido Fe, } \\
\%\end{array}$} & \multicolumn{2}{|c|}{ Recuperación Au } \\
\hline & & & & & & & $\begin{array}{c}\text { Pre., } \\
\%\end{array}$ & $\begin{array}{c}\text { Post., } \\
\%\end{array}$ \\
\hline Pirita & $\begin{array}{l}\text { T.f. } \\
\text { T.f. } \\
\text { T.f. } \\
\text { T.f. } \\
\\
\text { T.f. } \\
\text { T.f. } \\
\text { T.f. }\end{array}$ & $\begin{array}{c}35 \\
30-35 \\
30-35 \\
35 \\
\\
\\
30-35 \\
30 \\
30\end{array}$ & $\begin{array}{c}\text { Discont. } \\
\text { Discont. } \\
\text { Continuo } \\
\text { Discont. } \\
\\
\text { Discont. } \\
\text { Continuo } \\
\text { Discont. } \\
\text { Continuo }\end{array}$ & $\begin{array}{l}20 \\
- \\
- \\
15 \\
15 \\
15 \\
15 \\
18 \\
10 \\
10\end{array}$ & $\begin{array}{c}35 \\
30 \\
12 \\
14 \\
33 \\
70 \\
30 \\
5 \\
30 \\
16\end{array}$ & $\begin{array}{c}87 \\
60 \\
60 \\
45 \\
85 \\
100 \\
90 \\
90 \\
65 \\
50\end{array}$ & $\begin{array}{c}24 \\
25 \\
25 \\
7 \\
7 \\
7 \\
10 \\
21\end{array}$ & $\begin{array}{c}81 \\
90 \\
90 \\
70 \\
94 \\
100 \\
95 \\
95 \\
90 \\
90\end{array}$ \\
\hline $\begin{array}{c}\text { Arseno- } \\
\text { pirita }\end{array}$ & $\begin{array}{c}\text { T.f. } \\
\text { S161 } \\
\text { Sulfo. } \\
\text { T.f. } \\
\text { Mod. term. } \\
\text { Termof. } \\
\text { T.f. } \\
\\
\text { T.f.+T.t. } \\
\text { T.f. }\end{array}$ & $\begin{array}{l}30 \\
50 \\
60 \\
35 \\
\\
43 \\
35 \\
\\
35\end{array}$ & $\begin{array}{l}\text { Discont. } \\
\text { Discont. } \\
\text { Discont. } \\
\text { Continuo } \\
\text { Continuo } \\
\text { Continuo } \\
\text { Continuo } \\
\text { Discont. }\end{array}$ & $\begin{array}{c}5 \\
5 \\
5 \\
12 \\
2 \\
3 \\
15 \\
15 \\
12 \\
20\end{array}$ & $\begin{array}{c}8 \\
8 \\
8 \\
2 \\
7 \\
7 \\
6 \\
10 \\
7\end{array}$ & $\begin{array}{c}29 \\
47 \\
84 \\
70(\mathrm{As})\end{array}$ & $\begin{array}{c}6 \\
6 \\
6 \\
15 \\
15 \\
27 \\
55 \\
55 \\
71 \\
54\end{array}$ & $\begin{array}{l}56 \\
56 \\
91 \\
73 \\
63 \\
88 \\
90 \\
99 \\
92 \\
85\end{array}$ \\
\hline
\end{tabular}
desde el punto de vista cinético.

TABLA II.- Resultados recientes de ensayos de biolixiviación en laboratorio

TABLE II.- Recent laboratory bioleaching tests 
Prácticamente, en todas las experiencias se observan espectaculares aumentos del nivel de extracción de oro por cianuración tras la etapa de biolixiviación; sin embargo, desde el punto de vista cinético, los resultados son pobres, siendo necesario asumir tiempos de reacción que oscilan entre una y varias semanas.

Se tiene conocimiento (13-18) de un número considerable de operaciones a escala de planta piloto, e incluso a escala semi-industrial para la biolixiviación de estas menas. Los resultados obtenidos en ellas se muestran en la tabla III.

En general, la biolixiviación presenta grandes ventajas frente a los demás pretratamientos, ya sean piro o hidrometalúrgicos. Se trata de una alternativa con un bajo coste de reactivos y de instalaciones. Se realiza en condiciones de presión atmosférica y temperatura moderada, lo que provoca un abaratamiento adicional en los costes de operación y un menor impacto ambiental.

Sin embargo, según se observa en la tabla II, la biolixiviación de estas menas requiere tiempos de operación del orden de días, para conseguir una extracción de oro, en el posterior proceso de cianuración, del orden del $90 \%$. Esta cinética tan lenta influye negativamente en los costes de operación. Por este motivo, es deseable mejorar la velocidad del proceso para extender su aplicación a nivel industrial.

Para mejorar la cinética de la biolixiviación es necesario considerar el tipo de mecanismo de contacto que tiene lugar en cada caso concreto, según se resume en la tabla IV.

Las posibilidades de mejora en la cinética de los procesos de biolixiviación que se dan a través de un mecanismo de contacto directo, se basan en el desarrollo de cepas más activas, bien por el descubrimiento de nuevas especies naturales o bien por modificación de las ya conocidas, mediante técni-
TABLA IV.- Posibilidades para mejorar la cinética de biolixiviación

TABLE IV.- Chances to improve bioleaching kinetics

\begin{tabular}{|c|c|}
\hline $\begin{array}{l}\text { Mecanismo } \\
\text { de contacto }\end{array}$ & Mejoras \\
\hline Contacto directo & $\begin{array}{l}\text { * Desarrollo de cepas más activas } \\
\text { + Descubrimiento de nuevas } \\
\text { especies } \\
\text { + Adaptación de especies } \\
\text { conocidas } \\
\text { + Manipulación genética }\end{array}$ \\
\hline Contacto indirecto & $\begin{array}{l}\text { * Separación física de efectos } \\
\text { + Ataque químico } \\
\text { - activación térmica } \\
\text { - catálisis } \\
\text { + Regeneración biológica } \\
\text { - eliminar la abrasión } \\
\text { - suministro adecuado de } \\
\text { gases } \\
\text { - reactores de película } \\
\text { bacteriana soportada }\end{array}$ \\
\hline
\end{tabular}

cas de adaptación o de manipulación genética (19 y 20). Sin embargo, la implantación de estos cultivos va a tropezar con graves dificultades, especialmente la de evitar que dichas cepas preparadas pierdan su identidad tras un tiempo corto de operación.

Respecto a los procesos de biolixiviación, mediante mecanismo de contacto indirecto, existen posibilidades más prometedoras. Hay que considerar, en primer lugar, que en este mecanismo se dan simultáneamente en el reactor de biolixiviación dos procesos de distinta naturaleza: el ataque químico del ion férrico al sulfuro y la oxidación bacteriana del ion ferroso producido en la reacción. El primero de ellos es un proceso de naturaleza electroquímica mientras que el segundo es un proceso bioquímico.

TABLA III.- Plantas piloto y operaciones semicomerciales de biolixiviación de minerales y concentrados refractarios

TABLE III.- Pilot plants and semi-commercial operations for the bioleaching

\begin{tabular}{|c|c|c|c|c|c|c|c|c|}
\hline \multirow{2}{*}{ Planta } & \multirow{2}{*}{$\begin{array}{c}\text { Capacidad, } \\
\text { t/d }\end{array}$} & \multirow{2}{*}{$\underset{\mathrm{g} / \mathrm{t}}{\mathrm{Au}}$} & \multicolumn{2}{|c|}{ Distribución mineral } & \multirow{2}{*}{$\begin{array}{c}\text { T. resid., } \\
\text { h }\end{array}$} & \multirow{2}{*}{$\mid \begin{array}{c}\mathrm{S}=\text { oxidado } \\
\%\end{array}$} & \multirow{2}{*}{$\begin{array}{l}\text { Dp. } \\
\text { p/p \% }\end{array}$} & \multirow{2}{*}{$\underset{\%}{\operatorname{Recup.}} \mathrm{Au}$} \\
\hline & & & Py, \% & Apy, \% & & & & \\
\hline Equity Silver (Canadá) & 2 & 5,5 & & & 40 & 14 & & 75 \\
\hline Yellowknife (Canadá) & 10 & 68 & & ppal & 60 & 75 & 22,5 & 96 \\
\hline Fairview (S.A.) & 35 & 110 & 33 & 11 & 96 & 85 & & 92 \\
\hline Canon (EE.UU.) & & & & & 120 & 18 & 35 & 94 \\
\hline Moving (EE.UU.) & 0,95 & 23,2 & 40 & 19 & 15 & 75 & 14 & 90 \\
\hline Rusia & 0,06 & 10 & 14 & 8 & 60 & 50 & 80 & 95 \\
\hline BRGM (Francia) & 0,01 & 15 & 28 & 50 & 118 & 80 & & 92 \\
\hline Sao Bento (Brasil) & 150 & 30 & 16 & 18 & 11 & 30 & & \\
\hline
\end{tabular}


El ataque del ion férrico a los sulfuros metálicos se basa en las propiedades semiconductoras de estos materiales. En el proceso de lixiviación existe una transferencia electrónica desde el sólido hasta el ion férrico. Las zonas de generación y captación de electrones están separadas físicamente, de ahí la necesidad de que el mineral posea propiedades conductoras. La cinética de estas reacciones está muy influida por la temperatura: a temperatura ambiente son muy lentas y, sin embargo, a temperaturas moderadamente altas son considerablemente rápidas. Ello se debe a que, a diferencia de los conductores normales, un aumento de temperatura aumenta la conductividad de los semiconductores, mejorando así la difusión de electrones. Sin embargo, este aumento de temperatura perjudicaría seriamente a una población bacteriana mesófila.

Otro factor de gran importancia en la cinética de estas reacciones es la posibilidad de formación de pares galvánicos entre especies mineralógicas distintas. Cuando esto ocurre, el mineral con mayor potencial de electrodo induce la corrosión de otro de menor potencial que está en contacto con él. Así, en la asociación pirita-arsenopirita se favorece la disolución de la última. Estos pares galvánicos pueden formarse artificialmente con la adición de pequeñas cantidades de determinados cationes metálicos, que originen la formación de sulfuros de elevado potencial de electrodo, capaces de inducir la disolución de los sulfuros menos nobles. Esto ofrece una gran ventaja: realizar la lixiviación de forma selectiva (21). No obstante, los cationes normalmente utilizados para este efecto como, $\mathrm{Ag}^{+}, \mathrm{Hg}^{2+}, \mathrm{Bi}^{3+}$, etc. son muy nocivos para estos microorganismos (22).

Parece, pues, que toda mejora en el proceso de naturaleza electroquímica provoca una inhibición del proceso microbiológico. La única solución posible a este problema sería la separación física de estos dos procesos que tradicionalmente se han realizado sólo en un reactor.

Además, cuando la biolixiviación se realiza sólo en un reactor se da una serie de fenómenos que limitan de forma considerable la velocidad del proceso biológico. El origen de estos fenómenos está en el efecto abrasivo que ejercen las partículas del mineral sobre las bacterias. Esta abrasión introduce dos efectos negativos: en primer lugar, hace disminuir la población bacteriana activa y, en segundo lugar, aparecen en el medio sustancias orgánicas que provienen de la ruptura de la membrana celular y consiguiente disolución del citoplasma, que ejercen un acusado efecto inhibitorio sobre el crecimiento de las bacterias autótrofas. Esto hace que, tras varios días de operación, la actividad oxidativa de la suspensión bacteriana sea 20 veces menor que la del cultivo del cual procede. Por otra parte, estas bacterias requieren un adecuado suministro de dióxido de carbono y de oxígeno; el primero como fuente exclusiva de carbono, y el segundo como aceptor final de los pares electrónicos generados en los procesos que intervienen. Por tanto, es preciso emplear un dispositivo que permita un continuo suministro de estos dos gases en cantidades tan elevadas como permitan las condiciones de saturación del medio líquido.

Esto confirma que la cinética del proceso global mejorará considerablemente si se separan físicamente los dos efectos que tienen lugar en él. Esta separación física hace posible la activación específica de cada una de las etapas y, además, evita los efectos inhibitorios que puede tener la etapa puramente química sobre la microbiológica (23-27).

\section{OBJETIVO DEL TRABAJO}

Un estudio realizado en 1989 sobre los métodos de tratamiento de minerales primarios de oro, indicó que más del $94 \%$ de una producción total de $1677 \mathrm{t}$ de oro, se recuperó por técnicas simples (28). El otro $6 \%$ se obtuvo en plantas que utilizan una etapa de preoxidación antes de la aplicación de técnicas convencionales de recuperación. Los minerales tratados tienen características refractarias, por lo que la etapa de pretratamiento mejora el resultado neto de los procesos. Es importante destacar el valor de estas mejoras, ya que el capital y los costes de operación del pretratamiento pueden ser importantes, por lo cual la mejora debe ser suficiente para compensar estos elevados costes.

Si los minerales refractarios sólo inciden en el 6 $\%$ de la producción total, cabe preguntarse porqué existe tanto interés en su tratamiento. La respuesta se encuentra en el inventario de las reservas mundiales; la cantidad de mineral refractario es mucho mayor que las reservas de mineral fácil de tratar.

En el presente trabajo se estudian diferentes menas refractarias en matriz de sulfuros, a las cuales se les aplica la biolixiviación como pretratamiento para eliminar su refractariedad. Atendiendo a la composición química y mineralógica de cada una de las muestras, se elige un tratamiento específico, con idea de establecer un criterio a partir del cual se puedan tratar, mediante biolixiviación, menas de oro y plata de características semejantes a las aquí estudiadas.

\section{MÉTODOS EXPERIMENTALES}

\subsection{Caracterización de las muestras}

Las muestras fueron caracterizadas química y mineralógicamente, utilizando las siguientes técnicas: 
- Análisis químico de los elementos.

- Difracción de rayos $\mathrm{X}$.

- Visualización al microscopio óptico.

- Microscopía electrónica de barrido (SEM).

- Análisis de energía dispersiva de rayos $X$ (EDAX).

\subsection{Pruebas experimentales}

\subsubsection{Pruebas de lixiviación con cianuro}

Se realizaron pruebas de lixiviación con $\mathrm{NaCN}$ a los distintos materiales antes y después del tratamiento elegido. Las previas, tuvieron por objeto caracterizar los respectivos grados de refractariedad, y las posteriores, comprobar la efectividad del pretratamiento elegido.

\subsubsection{Condiciones experimentales}

Todas las pruebas se realizaron a temperatura ambiente $\left(20-25^{\circ} \mathrm{C}\right)$. El pH se ajustó a 12 con $\mathrm{NaOH}$ al $1 \%$ y se corrigió hasta este valor durante el transcurso de cada prueba. Durante las cianuraciones se suministró aire filtrado.

En este tipo de pruebas, una de las variables más importantes es la concentración de cianuro. Esta fue calculada en cada caso estimando la concentración de cianuro necesaria para complejar todo el oro y la plata del material, más 5 veces la concentración de cobre, si se disolviese todo el existente en el material, más un exceso de 400 ppm de cianuro. No obstante, en el caso de minerales con gran contenido de cobre, se siguió el criterio de no añadir más de 5.000 ppm de $\mathrm{NaCN}$.

Se controló periódicamente el pH y la concentración de cianuro libre. En los estudios cinéticos se controló también la concentración de oro en disolución. Al final de cada prueba, se analizó la concentración de oro y de plata en el licor, así como la de otros cationes específicos de cada prueba como hierro, arsénico y cobre. El residuo sólido se secó en una estufa a $80{ }^{\circ} \mathrm{C}$ y se analizó su riqueza en oro y plata por el método de ensayo al fuego.

La concentración de cianuro libre se valoró con una solución de $\mathrm{AgNO}_{3}$ 0,01M. La concentración de plata se analizó por espectrofotometría de absorción atómica, utilizando un patrón en solución de cianuro. La concentración de oro en la solución cianurada se analizó previa concentración con diisobutilcetona al $1 \%$ en Aliquat.

\subsubsection{Pruebas de lixiviación con sulfato férrico}

Con este tipo de pruebas se pretendía estudiar la capacidad del sulfato férrico para lixiviar el mate- rial objeto de estudio, la influencia de la adición de sulfato de plata como catalizador, así como el tiempo de lixiviación necesario.

Las condiciones experimentales se detallan en la tabla V.

Se realizaron tres tipos de pruebas con sulfato férrico:

- Pruebas de lixiviación no catalizadas.

- Pruebas de lixiviación catalizadas con plata (como sulfato de plata).

- Pruebas de lixiviación en varias etapas.

En estas últimas, se controló el potencial de la disolución con un electrodo combinado de potencial (Pt-Ag/AgCl). Cuando el potencial dejó de disminuir se consideró que la reacción se había detenido. A continuación, se retiró el licor agotado en agente lixiviante y se repuso con licor fresco de igual concentración a la inicial.

\subsubsection{Extracción de azufre}

Para eliminar el azufre elemental formado durante la lixiviación férrica de los sulfuros minerales, los residuos de lixiviación se trataron en un extractor Soxhlet con sulfuro de carbono.

\subsubsection{Ensayos de biolixiviación}

\subsubsection{Preparación del inóculo.}

En un reactor de $10 \mathrm{~L}$ termostatado a $31{ }^{\circ} \mathrm{C}$ se introdujeron $4 \mathrm{~L}$ de medio $9 \mathrm{~K}$ al $10 \%$ en sales básicas y a pH 1,50. Se inoculó con $800 \mathrm{~mL}$ de cultivos de Thiobacillus ferrooxidans crecidos en medio $9 \mathrm{~K}$, en estático, a $31{ }^{\circ} \mathrm{C}$. Se suministró aire con una bomba de membrana. Una vez consumido todo el sulfato ferroso, se repartió el cultivo entre dos reactores de $10 \mathrm{~L}$ y se añadieron $2,5 \mathrm{~L}$ de medio $9 \mathrm{~K}$, al $10 \%$ en sales básicas, a cada uno de ellos.

TABla V.- Condiciones experimentales de las pruebas de lixiviación férrica

TABLE V.- Ferric leaching tests; experimental conditions

\begin{tabular}{|l|l|}
\hline [Fe (III)] & $\begin{array}{l}10 \mathrm{~g} / \mathrm{L} \\
\mathrm{pH} \text { inicial }\end{array}$ \\
$\begin{array}{l}1,25 \text { (ajustado con ácido } \\
\text { sulfúrico) }\end{array}$ \\
Volumen de reacción & $4 \mathrm{~L}$ \\
Densidad de pulpa & $1 \%, \mathrm{p} / \mathrm{v}$ \\
Ag añadida & $1 \mathrm{mg} / \mathrm{g}$ de concentrado \\
Temperatura & $70{ }^{\circ} \mathrm{C}$ \\
\hline
\end{tabular}




\subsubsection{Lixiviación microbiológica}

Una vez preparado el inóculo se procedió a la realización de las pruebas de biolixiviación. Para ello, se completó hasta $10 \mathrm{~L}$ con las sales básicas del medio 9K al $10 \%$ y se añadieron $100 \mathrm{~g}$ de concentrado a cada reactor como substrato energético. Durante toda la prueba se suministró aire a los dos reactores con sendas bombas de membrana.

\subsubsection{Análisis y control}

Durante la evolución del cultivo se siguió controlando el $\mathrm{pH}$ y la concentración de $\mathrm{Fe}$ (III) en disolución.

Para controlar el grado de oxidación de la pirita fue necesario realizar previamente un lavado ácido para disolver el hierro que hubiera precipitado. El método analítico empleado fue el siguiente: $1 \mathrm{~mL}$ de muestra se trató durante 15 min en un agitador orbital con $\mathrm{HCl} 2 \mathrm{~N}$ para redisolver el hierro en forma de hidróxido y de jarositas. Esta solución se redujo en caliente haciéndole gotear $\mathrm{SnCl}_{2}$ al $15 \%$ (en $\mathrm{HCl} 6 \mathrm{~N}$ ), en exceso. De este modo, todo el $\mathrm{Fe}(\mathrm{III})$ se redujo a $\mathrm{Fe}(\mathrm{II})$. El exceso de $\mathrm{SnCl}_{2}$ se eliminó una vez enfriada la disolución con $10 \mathrm{~mL}$ de $\mathrm{HgCl}_{2}$ al $5 \%$

En la disolución se valoró el ion ferroso con dicromato potásico y difenil-amino-sulfonato de bario al $0,2 \%$ como indicador.

\section{MATERIALES}

Se estudiaron tres menas de oro en diferentes matrices. La primera de ellas es un concentrado de arsenopirita, la segunda un mineral de cobre y la tercera un concentrado de pirita. En las tablas VI y VII se presentan, respectivamente, sus composiciones químicas y mineralógicas.

\section{RESULTADOS Y DISCUSIÓN}

La tabla VIII muestra un resumen de los efectos obtenidos en la etapa de cianuración, después de los
TABLA VII.- Composición mineralógica

TABLE VII.-Mineralogical composition

\begin{tabular}{|l|c|c|c|}
\hline \multicolumn{1}{|c|}{ Especie } & $\begin{array}{c}\text { Concentrado } \\
\text { de FeAsS }\end{array}$ & $\begin{array}{c}\text { Mineral } \\
\text { de cobre }\end{array}$ & $\begin{array}{c}\text { Concentrado } \\
\text { de FeS }_{2}\end{array}$ \\
\hline Arsenopirita & $*$ & & \\
Pirita & $*$ & & $*$ \\
Calcopirita & $*$ & $*$ & $*$ \\
Pirrotina & $*$ & $*$ & \\
Bornita & & $*$ & \\
Calcosina & & $*$ & \\
Covelina & & $*$ & \\
Electrum & & $*$ & \\
Rejalgar & & $*$ & \\
Hessita & & & $*$ \\
Loelingita & & & \\
Esfalerita & $*$ & & \\
Bismutinita & $*$ & & \\
\hline
\end{tabular}

distintos pretratamientos realizados para cada uno de los minerales.

\subsection{Estudio del concentrado de arsenopirita}

En el caso del concentrado de arsenopirita se escogió la biolixiviación con separación de efectos, ya que el mecanismo de ataque bacteriano a este material es de contacto indirecto. Se realizaron tres tipos diferentes de pruebas de lixiviación para su posterior cianuración que fueron comparadas con una cianuración directa del concentrado. Con este estudio se pretende conocer la intensidad que ha de tener el tratamiento férrico para que sea efectiva la recuperación de metales preciosos.

En la primera prueba, el concentrado de arsenopirita se sometió a lixiviación con sulfato férrico durante $7 \mathrm{~h}$ sin catálisis. La extracción de arsénico durante este período de tiempo fue del $25 \%$. El residuo de lixiviación férrica, lavado con agua y seco, se cianuró durante $24 \mathrm{~h}$. La recuperación de oro obtenida en esta prueba, $63 \%$, es del orden, e incluso inferior, a la que se obtuvo al cianurar directamente $(66 \%)$.

El segundo pretratamiento consistió en una lixiviación con sulfato férrico más intensa. Para ello se realizó una prueba de 12 h de duración catalizada

TABLA VI.- Composición química

TABLE VI.- Chemical composition

\begin{tabular}{|l|c|c|c|c|c|c|}
\hline \multicolumn{1}{|c|}{ Material } & $\mathrm{Fe}, \%$ & $\mathrm{~S}, \%$ & $\mathrm{As}$ & $\mathrm{Cu}$ & $\mathrm{Au}, \mathrm{g} / \mathrm{t}$ & $\mathrm{Ag}, \mathrm{g} / \mathrm{t}$ \\
\hline Concentrado de FeAsS & 34,6 & 25 & $23 \%$ & $2.700 \mathrm{~g} / \mathrm{t}$ & 14 & 88 \\
Mineral de cobre & 11 & 10,3 & $2.400 \mathrm{~g} / \mathrm{t}$ & $19,4 \%$ & $20-70$ & $330-380$ \\
Concentrado de $\mathrm{FeS}_{2}$ & 20 & 24 & $1,3 \%$ & $1.000 \mathrm{~g} / \mathrm{t}$ & 12 & 22 \\
\hline
\end{tabular}


TABLA VIII.- Efectos de los pretratamientos en la posterior cianuración

TABLE VIII.- Effect of pretreatments on the following cyanidation

\begin{tabular}{|c|c|c|c|c|c|c|c|}
\hline \multirow{2}{*}{ Material } & \multirow{2}{*}{ Pretratamiento } & \multirow{2}{*}{$\mathrm{t}, \mathrm{h}$} & \multirow{2}{*}{ Etapas } & \multirow{2}{*}{$\begin{array}{c}\text { Extracción, } \\
\%\end{array}$} & \multicolumn{3}{|c|}{ Cianuración } \\
\hline & & & & & $\mathrm{t}, \mathrm{h}$ & $\mathrm{Au}, \%$ & $\mathrm{Ag}, \%$ \\
\hline Concentrado FeAs & Ninguno & 0 & 0 & - & 24 & 66 & 30 \\
\hline Concentrado FeAs & Lixiviación férrica & 7 & 1 & $25 \mathrm{As}$ & 24 & 63 & 46 \\
\hline Concentrado FeAs & Lixiviación férrica catalizada & 12 & 4 & $66 \mathrm{As}$ & 24 & 80 & 38 \\
\hline Concentrado FeAs & $\begin{array}{l}\text { Lixiviación férrica catalizada y } \\
\text { extracción de azufre }\end{array}$ & 12 & 4 & $85 \mathrm{As}$ & 24 & 91 & 70 \\
\hline Mineral de cobre & Ninguno & 0 & 0 & - & 24 & 27 & 1 \\
\hline Mineral de cobre & Lixiviación férrica catalizada & 14 & 1 & $99,5 \mathrm{Cu}$ & 34 & 95 & 92 \\
\hline Concentrado $\mathrm{FeS}_{2}$ & Ninguno & 0 & 0 & - & 24 & 30 & \\
\hline Concentrado $\mathrm{FeS}_{2}$ & Lixiviación directa & 220 & 1 & $100 \mathrm{FeS}_{2}$ & 24 & 77 & \\
\hline Concentrado $\mathrm{FeS}_{2}$ & $\begin{array}{l}\text { Biolixiviación directa y lavado } \\
\text { ácido }\end{array}$ & 220 & 1 & $98 \mathrm{Fe}$ & 4 & 90 & \\
\hline Concentrado $\mathrm{FeS}_{2}$ & Biolixiviación directa y lavado ácido & 220 & 1 & $98 \mathrm{Fe}$ & 24 & 95 & \\
\hline
\end{tabular}

con plata. Esta prueba se llevó a cabo por etapas, es decir, se retiró del reactor el licor, una vez agotado en $\mathrm{Fe}(\mathrm{III})$, reponiéndose con sulfato férrico fresco. El criterio de agotamiento del agente lixiviante se basó en la variación del potencial del licor.

En estas condiciones se consiguió extraer el 66 $\%$ del arsénico contenido en la muestra. El residuo empobrecido en arsénico, lavado y seco, se cianuró en las condiciones indicadas.

Puede observarse que la extracción de oro aumentó considerablemente después de este pretratamiento, alcanzándose el $80 \%$. No ocurrió lo mismo con la plata, de la que solamente se extrajo el $38 \%$. Este dato de extracción de plata está referido a toda la presente en el sólido, es decir, la que contiene el concentrado de forma natural y la adicionada como catalizador en la etapa de pretratamiento. Por tanto, esta recuperación de plata no es comparable con las obtenidas en pruebas anteriores. Aunque el resultado no sea satisfactorio, se corresponde con una concentración de plata en el licor mucho mayor que las alcanzadas anteriormente.

En el licor se detectó la presencia de sulfocianuro, especie que surge de la reacción entre el azufre elemental, presente en el residuo como producto de la lixiviación férrica, y el cianuro. La presencia de sulfocianuro puede hacer que precipite el oro y, además, puede formar complejos con la plata. Por tanto, la capa de azufre elemental formada durante la lixiviación con sulfato férrico origina graves problemas en el posterior tratamiento con cianuro, puesto que propicia la formación de sulfocianuro que puede retardar la disolución del oro, aumentar el consumo de cianuro y bajar la extracción de la plata.

De acuerdo con estos resultados, se realizó un tercer pretratamiento en el que se extrajo el azufre elemental, formado en la etapa de lixiviación férrica, para evitar los efectos negativos que produce.

Después de $24 \mathrm{~h}$, el resultado fue una extracción del $91 \%$ del oro y $70 \%$ de la plata. En este caso no se detectó sulfocianuro en el licor de cianuración, lo cual indica que la extracción del azufre fue efectiva.

\subsection{Estudio del mineral de cobre}

En el caso del mineral de cobre, el pretratamiento consistió en una lixiviación con $10 \mathrm{~g} / \mathrm{L}$ de sulfato férrico catalizada con $1 \mathrm{mg}$ de plata/g de mineral a tratar. Después de la eliminación del cobre se extrajo el azufre elemental formado con $\mathrm{CS}_{2}$. El residuo pobre en cobre y en azufre se lixivió con cianuro. A la vista de los resultados (Tabla VIII) puede decirse que el pretratamiento utilizado permite casi la total extracción de oro por cianuración, mientras que si no se realiza pretratamiento, el oro extraido no supera el $23 \%$. Se consigue, además, recuperar el $92 \%$ de la plata, considerando la propia del mineral y la adicionada como catalizador.

\subsection{Estudio del concentrado de pirita}

En el tercer material estudiado, como su componente mayoritario es pirita y este material es atacado por los microorganismos mediante un mecanismo de contacto directo, se utilizó como pretratamiento la técnica convencional de biolixiviación.

Se prepararon dos residuos de lixiviación microbiológica del concentrado para su posterior cianuración. Una vez eliminada toda la pirita que contenía el primero de ellos, se lavó con agua y se lixivió con cianuro. El segundo residuo fue sometido a un 
lavado con $\mathrm{HCl} 1 \mathrm{~N}$ antes de su cianuración para eliminar los precipitados de hierro que se formaron durante la etapa de biolixiviación.

En ambos casos, la biolixiviación mejora espectacularmente los resultados de la cianuración, 77 y $95 \%$ de oro, respectivamente frente al $30 \%$ de la cianuración directa. En la figura 1 se muestran las curvas cinéticas de la extracción de oro para ambas pruebas.

Cuando se realiza lavado ácido, a las $4 \mathrm{~h}$ de tratamiento con cianuro, ya se ha conseguido lixiviar el $90 \%$ del oro; posteriormente, la extracción aumenta lentamente hasta alcanzar el $95 \%$ a las 24 h. En el caso en que no se realiza lavado ácido, la cinética es más lenta. La explicación puede estar en la presencia de precipitados de hierro formados como productos de la biolixiviación, que pueden cubrir las partículas de oro y, por tanto, evitar que el cianuro tenga acceso a ellas. Estos compuestos se descomponen en las condiciones alcalinas que hay durante la cianuración y es necesario que transcurra el tiempo suficiente para que se destruyan y el oro quede libre para su cianuración.

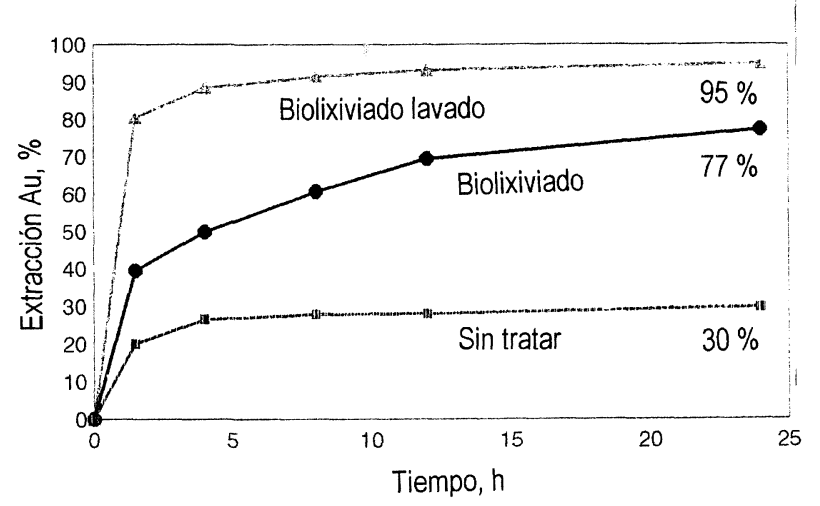

Fig. 1.- Evolución del porcentaje de extracción de oro para cianuraciones del concentrado de pirita sin tratar y con distintos pretratamientos.

FIG. 1.- Gold extraction during cyanidation of fresh pyrite concentrate and pretreated ones.

\section{CONCLUSIONES}

- La refractariedad del concentrado de arsenopirita puede eliminarse satisfactoriamente mediante lixiviación férrica catalizada con plata y extracción posterior del azufre elemental formado. Con este pretratamiento se consigue una recuperación del $90 \%$ del oro y del $70 \%$ de la plata en la posterior lixiviación con cianuro.

- La refractariedad del mineral de cobre se elimina mediante la lixiviación férrica catalizada con plata y posterior extracción del azufre elemental formado. La extracción del $99.5 \%$ del cobre permite recuperar por cianuración el $95 \%$ del oro y el $92 \%$ de la plata.

- Después de 10 días de biolixiviación por contacto directo con un cultivo de Thiobacillus ferrooxidans, se disuelve el $100 \%$ del hierro presente en el concentrado de pirita. Después de eliminar la pirita por biolixiviación, se consigue extraer por cianuración el $95 \%$ del oro que contiene el concentrado.

- Durante la biolixiviación por contacto directo del concentrado de pirita precipitan compuestos de hierro que pueden cubrir las partículas de oro, impidiendo el acceso de los iones cianuro en la posterior etapa de cianuración. Estos compuestos pueden eliminarse mediante lavado ácido o simplemente con una etapa de aireación previa en condiciones alcalinas.

- Puede afirmarse que la biolixiviación es un pretratamiento eficaz para menas refractarias de oro y de plata en matriz de sulfuros. En el caso de menas en matriz de sulfuros de cobre y/o en matriz de sulfuros de arsénico, la biolixiviación puede realizarse por un mecanismo de contacto indirecto con separación de efectos. En el caso de menas en matriz de pirita es necesario el contacto directo entre el sulfuro y los microorganismos.

\section{REFERENCIAS}

(1) GuAY, W.J. "The treatment of refractory gold ores containing carbonaceous materials and sulphides". Proc. 110th AIME Meet. Gold and Silver Leaching, Recovery and Economics. SchlitT, W.J.; LARSON, W.C.; Hiskey, J.B. (Eds) SME-AIME, Chicago (EE.UU.), 1981: 22-26.

(2) Robinson, P.C."Mineralogy and treatment of refractory gold from the Porgera Deposit, New Guinea". Inst. Min. Metall., 92, 1983: 83-89.

(3) Gasparrini, C. C.I.M. Bull., 76, 1983: 144-153.

(4) Schweigart, H. y Lienenberg, W.R. "Mineralogy and chemical behaviour of some refractory gold ores from the Barbeton”. N.I.M. 1986. Rep. 8,

(5) JHA, M.C. Miner. Process. Extr. Metall. Rev., 3, 1987: 331-352.

(6) Demopoulos, G.D. "Gold extraction from refractory ores". Professional Development Seminar in Mineral Processing of Gold Ores, McGill Univ. 1-3 mayo 1985.

(7) Karavaiko, G.I., Chuchalilin, L.K., Pivovarova, B.A., Yemel'yanov, B.A. y Dorofeyef, A.G. "Microbial leaching of metals from arsenopyrite containing concentrates", R.W. LAWRENCE, R.M.R. BRANION y H.G. EBNER (Eds.). Fundamentals and Applied Biohydrometallurgy, Elsevier, Amsterdam, 1986: 115-126.

(8) Morin, D. y Olliver, P. "Biolixiviation de concentre sulfure arsenie d'or refractaire pour extration de l'or et elimination de l'arsenic", Comunicación presentada al Gold'89, Toulouse (Francia), 1989. 
(9) Groudev, S.N. y Groudeva, V.I. "Microbial leaching of gold from ores and minerals wastes by means of heterotrophic bacteria", Comunicación presentada al Int. Symp. of Biohidrometallurgy'89, Wyoming (EE.UU.), 1989.

(10) Hutchins, S.R., Brierley, J.A. y Brierley, C.L. Proc. Mineral, 8, 1987: 53-66.

(11) Lawrence, R.W. y Bruynestein, A. C.I.M. Bull, 76 (857), 1983: 107-110.

(12) Ralph, R., Hacke, R.P., Wright, F.R. y GoRmLey, F.R. "Bacterial leaching of refractory gold ores", Comunicación presentada al Int. Symp. of Biohidrometallurgy'89, Wyoming (EE.UU.), 1989.

(13) Morin, D. y Olliver, P. "Pilot plant practice of continous bioleaching of a gold refractory sulphide concentrate with a high arsenic content", Comunicación presentada al Int. Symp. of Biohidrometallurgy'89, Wyoming (EE.UU.), 1989.

(14) Handsford, G.S. y Chapman, J.T. Miner. Eng., 5 (6), 1992: 597.

(15) Paponetti, B.A., Ubaldini, S., Abbruzzese, C. y Toro, L. "Biometallurgy for the recovery of gold from arsenopyrite ores", SMith, R.W. y MisRa, M. (Eds.), Minerals processing TMS, 1991: 179-188.

(16) Komnitsas, C. y Pooley, F.D. Miner. Eng., 3 (3/4), 1990: 295.

(17) Lazer, M.J., Southwood, M.J. y Southwood, A.J. "The release of refractory gold from sulphide minerals during bacterial leaching", Proc. Int. Conf. on Gold, vol 2, Inst. Min. Metall., Johanesburgo (Suráfrica), 1986: 287-297.

(18) HandsFord, G.S. y Drossou, M.A. "A propagating pore model for the batch bioleach kinetics of refractory goldbearing pyrite", Comunicación presentada al Int. Symp. of Biohidrometallurgy. Warwick (Reino Unido), 1988: 345-358.

(19) Rawlings, D.E., Pretorius, I.M. y Woods, D.R. J. Biotechnol., 1, 1984: 129-133.

(20) Holmes, D. y HAQ, R."Adaptation of Thiobacillus ferrooxidans for industrial applications". Comunicación presentada al Int. Symp. of Biohidrometallurgy'89, Wyoming (EE.UU.), 1989.

(21) Barriga, F., Palencia, I. y Carranza, F. Hydrometallurgy, 19, 1987: 159-167.

(22) Hoffman, L. y Hendik, J. Biotech. Bioeng., 18, 1976: 1.161 .

(23) Palencia, I, Carranza, F. y Garcia, M.J. Hydrometallurgy, 23, 1990: 191-202.

(24) Carranza, F., Garcia, M.J., Palencia, I. y Pereda, J. Hydrometallurgy, 24, 1990: 67-76.

(25) Carranza, F., Iglesias, N., Romero, R. y Palencia, I. FEMS Microbiol. Rev. 11, 1993: 129-138.

(26) Iglesias, N. y Carranza, F. Hydrometallurgy, 34, 1994: 383-395.

(27) Palencia, I, Carranza, F., Barriga, F y Garcia, M.J. Pat. Esp. no 2009104-8803370. 1989.

(28) Marsden, J. y House, I. "The chemistry of gold extraction" Simon \& Shuster International Group, R.U., 1992: 509. 